\title{
Enhancing Teacher Effectiveness in Spain: A Pilot Study of The RULER Approach to Social and Emotional Learning
}

\author{
Ruth Castillo $^{1}$, Pablo Fernández-Berrocal ${ }^{1} \&$ Marc A. Brackett $^{2}$ \\ ${ }^{1}$ Faculty of Psychology, University of Málaga, Spain \\ ${ }^{2}$ Yale Center for Emotional Intelligence, Yale University, USA \\ Correspondence: Dr. Ruth CastilloGualda, Faculty of Psychology, University of Málaga. Department of \\ Experimental Psychology, 29071 Málaga, Spain. Tel: 34-952-132-597. E-mail: ruthcastillo@uma.es
}

Received: July 3, 2013 Accepted: July 15, 2013 Online Published: August 16, 2013

doi:10.11114/jets.v1i2.203 URL: http://dx.doi.org/10.11114/jets.v1i2.203

\begin{abstract}
This study examined the effects of an evidence-based social and emotional learning (SEL) program, The RULER Approach to Social and Emotional Learning (RULER), on teacher self reports of engagement, teacher-student interactions, and burnout. Participants were 47 teachers from 19 public schools in Spain who either volunteered for training on RULER $(n=24)$ or eLearning $(n=23)$. Multivariate Analysis of Covariance (MANCOVA) was conducted separately for each outcome. Teachers in the RULER as compared to eLearning group had significantly higher scores on many outcomes even after controlling for gender, age, trait affect, and personality, as well as pre-test scores on all outcomes. These findings extend the literature on the effectiveness of SEL programs for the improvement of teacher practices; they also advance our understanding of possible mechanisms for promoting high-quality professional development.
\end{abstract}

Keywords: SEL, adult development, teaching practice, Spanish schools, emotional intelligence

\section{Introduction}

Teachers have a dramatic impact on students' positive development and the overall success of their classrooms. Effective teachers promote positive interactions and influence a wide range of student-level outcomes, including cognitive, emotional and social functioning (Cornelius-White, 2007; Van Uden, Ritzen, \& Pieters, 2013; Wubbels \& Brekelmans, 2006). What is more, teachers who are able to create optimal learning environments, including active learning practices and adequate communication between and among students and the teacher, have students who perform better academically (Wubbels \& Brekelmans, 2006). Given these findings, there is increasing interest in programming that can help teachers to promote these student outcomes (Baker, 2006; Patrick, Ryan, \& Kaplan, 2007; Pianta, Belsky, Vandergrift, Houts, \& Morrison, 2008; Sutton \& Wheatley, 2003).

School-based programming that promotes social and emotional learning (SEL) shows great promise to enhance both teacher practices and student performance (Durlak, Weissberg, Dymnicki, Taylor, \& Schellinger, 2011). SEL programs positively influence classroom climate, teacher effectiveness, academic performance, and students' social and emotional skills development (Brackett, Rivers, Reyes, \& Salovey, 2012; Hagelskamp, Brackett, Rivers, \& Salovey, 2013; Rivers, Brackett, Reyes, Elbertson, \& Salovey, 2013; Greenberg et al., 2003). Less is known about how SEL programs affect teachers' attitudes, beliefs, and behavior, however.

\subsection{Teacher Engagement and Social Functioning in Classrooms}

A positive emotional climate is one critical factor to both teachers' and students' well being and performance (Hamre \& Pianta, 2001). It is well known that the display of positive emotions, one critical component of a classroom emotional climate, is associated with greater psychological health. Among teachers, the experience of positive emotions likely can help them optimize personal resources to deal with everyday challenging situations (Canrinus, Helms-Lorenz, Beijaard, Buitink, \& Hofman, 2012; Fredrickson, 2000). Indeed, educators who express positive emotions - display positive facial expressions, vocal intonations, and body language - tend to have students who both report greater interest and enjoyment in their classrooms and perform better academically (Reyes, Brackett, Rivers, White, \& Salovey, 2012; Wubbels \& Brekelmans, 2006). A positive 
emotional climate also influences students' affiliation with teachers and classroom behavior (Brackett, Rivers, Reyes, \& Salovey, 2012). In contrast, less positive classrooms tend to have lower levels of achievement and greater conflict (Hamre \& Pianta, 2005). Thus, a teacher's ability to create a caring and supportive environment is critical to all aspects of teacher and student success (den Brok, Brekelmans and Wubbels, 2004; Canrinus et al., 2012; Patrick, Hisley, \& Kempler, 2000).

\subsection{Teacher Burnout and Stress in School Settings}

Unfortunately, many teachers report high levels of stress - or the absence of positive emotions in school (Johnson, Cooper, Cartwright, Donald, Taylor, \& Millet, 2005). Stressors include non-useful policies, time-consuming bureaucratic tasks, and challenging students, all of which make the teaching profession one of the most demanding occupations (Elvira \& Cabrera, 2004; Hargreaves, 2000). Indeed, many educators report poor physical and psychological health due to high levels of stress and job dissatisfaction (Johnson et al., 2005; Travers \& Cooper, 1993). Further, stressed and dissatisfied educators tend to have negative self-views about their teaching, less professional commitment, are absent more often (Borg, Riding, \& Falzon, 1991), and have students' with lower academic performance (Wubbels \& Brekelmans, 2006).

Not surprisingly, burnout and teacher engagement are negatively correlated (Hakanen, Bakker, \& Schaufeli, 2006; Klassen et al., 2012). Teacher burnout may negatively affect several aspects of classroom functioning, such as positive interactions with their students or the provision of evaluative feedback (Travers, 2001). One possible solution to decreasing teacher stress and burnout, building healthy relationships, and enhancing student performance is to develop teachers' social and emotional skills. These skills have been shown to help teachers deal with conflict, manage unpleasant emotions, and improve classroom climate (Brackett, Palomera, Mojsa-Kaja, Reyes, \& Salovey, 2010; Carson, Plemmons, Templin, \& Weiss, 2011; Sutton, 2004).

Overall, it seems that the enhancement of variables directly related to optimal teaching practices, such as teachers' overall satisfaction and commitment to their work, as well as teachers' sensitivity to their students' needs beyond the academic matters, would contribute to better classroom functioning and school success.

\subsection{Social and Emotional Learning Interventions}

Social and Emotional Learning (SEL) programs are designed to promote self and social awareness, emotion regulation, responsible decision making, problem solving and relationship management (Greenberg et al., 2003; Zins, Weissberg, Wang, \& Walberg, 2004). Past research has shown positive effects of interventions that promote SEL. Among students, SEL increases several outcomes related to positive youth development, including emotional skills, prosocial behavior, relationship quality, and academic performance (Brackett, Rivers, Reyes, \& Salovey, 2012; see also Durlak, et al., 2011, for a recent meta-analysis of SEL programs). Together, these findings provide evidence that SEL programs help to create more productive and successful learning environments.

Evidence of the effectiveness of SEL programs outside the U.S. is limited, however (Castillo, Salguero, Fernández-Berrocal, \& Balluerka, 2013; El Hassan \& Mouganie, 2013; Humphrey, Kalambouka, Wigelsworth \& Lendrum, 2010; Hutchings, Bywater, Gridley, Whitaker, Martin-Forbes \& Gruffydd, 2011; Ruiz-Aranda, Castillo, Salguero, Cabello, Fernández-Berrrocal \& Balluerka, 2012). Eighty-three percent of the studies in the recent meta-analysis included samples from the U.S. (Durlak et al., 2011), making it difficult to test the generalizability of SEL programming outside U.S. In addition, very few studies have focused on enhancing teacher-specific outcomes such as classroom supportiveness and other teaching practices. For example, just one large randomized controlled trial in 62 American schools has shown that teachers who integrated SEL instruction in their classrooms demonstrated more positive emotions, greater personal connections with their students, enhancing students' engagement by incorporating their ideas, and increasing cooperative learning, as rated by outside observers (Rivers et al., 2013). Because teachers are the primary implementers of SEL programs, it is important to know how SEL practices influence teaching practices. The RULER Approach to Social and Emotional Learning (RULER) is one evidence-based program that puts great emphasis on teacher development.

\subsubsection{The RULER Approach to SEL}

RULER is a universal SEL intervention that provides training for teachers and school leaders in addition to a classroom-level curriculum for students. RULER is grounded in the ability model of emotional intelligence (Mayer \& Salovey, 1997) and is designed to enhance five key emotional skills represented by the acronym RULER (Brackett, Rivers, Maurer, Elbertson, \& Kremenitzer, 2011). Recognition of emotion refers to the identification of changes in physical, emotional, and behavioral experiences of emotion in oneself and others. Understanding of emotion refers to knowledge about the causes and consequences of emotions. Labeling emotion refers to communicating the language of emotion using a sophisticated vocabulary. Expression of 
emotion refers to expressing emotions in socially appropriate ways. Regulating emotion refers to the effective management of emotions, thoughts, and behaviors to achieve goals (for additional information, see www.ruler.yale.edu).

RULER provides teachers with tools and strategies to (1) demonstrate and communicate their emotions during in everyday instruction, (2) validate and foster their students' feelings and thoughts, and (3) use emotions in the classroom to guide student thinking. The four primary tools in RULER, the "Anchors," are designed for both personal and professional development. Educators (teachers and school leaders) are provided with tools and activities designed to foster both their own and their students' emotional intelligence.

\subsection{The Present Study}

The effectiveness of SEL programs like RULER on specific work-related outcomes and social functioning has not been studied among teachers outside the U.S. This research intends to fill this important gap on a sample of Spanish teachers. This pilot study used a pretest-posttest design to test the effectiveness of RULER on several teacher-reported outcomes - engagement, teacher-student interactions, and burnout - related to optimal teaching practices in Spanish schools. According to prior research on the positive impact that SEL instruction has on the enhancement of teaching performance and classroom climate (Rivers et al., 2013), we hypothesized that teachers who implemented RULER (as compared to a comparison group of teachers who received non SEL-related training) would report greater levels of engagement, higher-quality teacher-student interactions, and decreased burnout after controlling for teacher personality and trait affect, two variables that have been traditionally linked to work-related outcomes (Carson et al., 2011; Langelaan, Bakker, van Doornen, \& Schaufeli, 2006).

\section{Methods}

\subsection{Participants}

Participants were 47 teachers from 19 public schools located in southern Spain (70\% females). Every year the Department of Education offers teachers who work in public schools the possibility of increasing their skills through a wide-range of trainings. Teachers apply to participate in the training that interests them; they are not required to take any particular courses. The research team made an official proposal to the Department of Education in Spain to offer training in SEL. The sample was comprised of 24 teachers who voluntarily decided to participate in in SEL training (i.e., RULER training) and 23 teachers who voluntarily chose to participate in eLearning training; the latter group served as the comparison group. Both trainings were implemented following the procedures for official trainings supported by the Department of Education. For example, both trainings met for the same amount of time, during the same academic period, and once accepted, attendance was required. Teachers were between 25 and 59 years old $(M=44.27), 11$ were kindergarten teachers $(23 \%), 14$ were primary school teachers $(30 \%)$, and 22 were secondary school teachers (47\%). The average years of teaching experience for these teachers was approximately 15 years $(S D=9.7)$. The research study protocol was approved by the Technical Council of the Ethical Committee of the University of Malaga. Below, each of the training programs is described in more detail.

\subsection{Materials and Procedures}

This study used a pre-test-post-test design, extended across six months (from January to June), during the 2011 academic year. Pre-test data were collected in January 2011 in a 1-hour session before the beginning of the trainings. Post-test data were collected in June 2011 in a 1-hour session approximately one month after the trainings. At both time points, all participants (RULER and eLearning groups) completed the surveys, including: socio-demographic characteristics, trait affect, personality, work engagement, teacher-student interactions, and burnout.

\subsubsection{Training}

RULER. The first author received extensive training by the developers of RULER and received the materials and guidelines to ensure the accurate implementation of the program. All RULER materials and presentations were translated into Spanish. The intervention focused on teaching teachers how to implement the four Anchor Tools, described briefly below. During the training, teachers observed sample lessons from the instructor and worked in small groups to practice the lessons. The researcher observed the lessons and offered feedback and suggestions for best practices. Regular check-ins regarding the quality of implementation between the researcher and program developer took place throughout the period. Surveys to determine whether RULER tools were being implemented in the classroom were collected randomly throughout the training period.

Teachers participated in a total of 30-hours of training across the six-month period. The training accomplished several goals, including (a) honing teachers' RULER skills to help them become more effective decision makers, improve personal and professional relationships, and cope with stress, and (b) learn how to build the necessary 
foundation to integrate RULER into their existing curriculum, including the RULER Anchor Tools.

The RULER Anchor Tools integrate into the school day and are adapted to every level of teaching (preschool, primary or secondary). The first tool, The Charter, is a statement about the school and classroom environment that a group (of teachers in the training; students in the classroom) is expected to maintain. Participants consider how they want to feel at school, what they need to do in order to experience those feelings consistently, and develop guidelines to both prevent and manage challenging situations including conflict. The second tool, The Mood Meter, teaches participants to consider two dimensions of emotions: valence or pleasantness and arousal or energy level. Teachers and students regularly plot their moods and use the Mood Meter to develop their RULER skills such as a sophisticated emotion vocabulary. The third tool, The Meta-Moment builds self-regulation by teaching educators to "expand the space" between a trigger and one's emotional response in order to improve reflective practices and respond effectively with research-based strategies to emotionally-charged situations. Finally, The Blueprint is comprised of a series of questions designed to develop empathy and perspective-taking skills, and also to help adults and children resolve conflict healthily. Participants work with each other to identify healthy solutions for past conflicts or real-time situations. (For a full description of the RULER Anchors, see Brackett et al., 2011).

$\boldsymbol{e}$-Learning. Teachers in the eLearning group also attended 30 hours of training across the same six-month period. These teachers learned basic tools and techniques for implementing technology in their classrooms. Specifically, the eLearning training accomplished several objectives, including (a) instructing teachers how to use digital blackboards in their classrooms; (b) providing teachers with an understanding of different software for digital blackboards; (c) facilitating teachers' use of e-materials and multimedia; and (d) helping teachers to create e-materials and participative work groups.

\subsubsection{Measures}

Participants in RULER and eLearning training completed the following measures:

Work engagement. The Spanish version of the Utrecht Work Engagement Scale was administered (UWES; Schaufeli, Salanova, González-Romá, \& Bakker, 2002). Engagement, as measured by this scale, is defined as a positive mental state of workplace performance. The questionnaire has 15 items scored on a seven-point Likert scale ranging from $(0=$ never to $6=$ always $)$, which are grouped into three dimensions; vigor, which is defined as high levels of energy and mental resilience while working, the willingness to invest effort in one's work, and persistence in the face of difficulties; dedication, which involves a sense of significance, inspiration, pride, and challenge about work; and absorption, which is related to full concentration and engagement in one's work, whereby times passes quickly and one has difficulties detaching oneself from work. Scale reliabilities (alphas) at pre-test and post-test for the full sample were: vigor $=.91$ and .84 ; dedication $=.91$ and .87 ; absorption $=.75$ and .86 .

Teacher- Student interactions. A Spanish translation of the Emotion-Focused Interaction Scale (EFIS; Rivers et al., 2013), which assesses a range of behaviors reflecting positive interpersonal relationships between teachers and students, was employed. The 12 -item scale uses a five-point Likert scale $(1=$ never to $5=$ very often $)$ to assess three dimensions of teacher-student relationships: personalized student interactions, the frequency with teachers believe they engage in personalized, positive interactions with students; responses to emotions, the frequency with which teachers believe they inquire about and respond to their students' emotional well-being; and caring beyond classroom, the frequency with which teachers believe they show concern for their students beyond academic matters. Scale reliabilities (alphas) at pre-test and post-test for the full sample were similar to the English version: personalized student interactions $=.71$ and .76 ; responses to emotions $=.89$ and .89 ; caring beyond classroom $=.90$ and .86 , respectively.

Burnout. The Spanish version of the Maslach Burnout Inventory-Educators Survey (MBI-ES; Maslach, Jackson, $\&$ Leiter, 1996) was used to assess burnout. The scale consists of 22 items rated on a 6 -point scale $(1=$ never; 6 = every day). The questionnaire is designed to assess three aspects of burnout: emotional exhaustion, which reflects educators' degree of stress; depersonalization, which involves cognitive distancing, indifference or cynical attitude while at work; and personal accomplishment, which is related to feelings of efficacy and success. In contrast to the other two subscales, higher mean scores on personal accomplishment correspond to less burnout. Scales reliabilities for this sample (alphas) for pre-test and post-test for the full sample were: emotional exhaustion $=.87$ and $.89 ;$ depersonalization $=.56$ and $.75 ;$ personal accomplishment $=.82$ and .79 respectively.

Trait affect. A Spanish version of the Positive and Negative Affect Schedule (PANAS; Watson, Clark \& Tellegen, 1988) was used to assess trait affect. This self-report measure contains two 10-item scales related to the experience of positive and negative affect within a specified time frame. In this study, teachers rated how 
well each feeling described how they typically felt at work, using a five-point scale $(1=$ very slightly; $5=$ extremely). Scales reliabilities at pre-test and post-test for the full sample were: positive affect $=.89$ and .89 ; negative affect $=.89$ and .90 respectively.

Personality. Personality was measured with the Big Five Inventory (BFI-44; John, Donahue \& Kentle, 1991), Spanish version (Benet-Martinez \& John, 1998). This questionnaire provides a measure of five broad dimensions of personality, openness to experience, conscientiousness, extraversion, agreeableness and neuroticism. The scale has 44 items rated on a 5-point Likert scale. Scales reliabilities at pre-test and post-test for the full sample were: .83 and $.82 ; .75$ and $.80 ; .75$ and $.77 ; .61$ and .75 ; and .80 and .79 respectively.

\subsubsection{Statistical Analyses}

To compare the effects of each training on teacher outcomes, data were analyzed using SPSS software. First, we examined whether RULER and eLearning groups differed systematically at baseline. Multivariate Analysis of Covariance (MANCOVA) was performed separately for each of the primary variables of interest (engagement, teacher-student interactions, and burnout), including the covariates with their respective subscales (age, gender, trait affect, and personality). Then, to analyze the change from pre-test to post-test, three separate MANCOVA were performed, again, on the primary variables of interest with the covariates include in the models. Effect sizes were computed using partial $\eta^{2}$.

\section{Results}

Table 1 reports the means and standard deviations for each outcome at baseline for both the RULER and eLearning groups. At baseline, results yielded no statistically significant differences between measures of engagement, Wilk's lambda $F(3,43)=.69, p=.56$; teacher-student interactions, Wilk's lambda $F(3,43)=.25$, $p=.86$, burnout, Wilk's lambda $F(3,43)=.33, p=.80$; trait affect, Wilk's lambda $F(2,44)=.73, p=.49$; or personality, Wilk's lambda $F(5,41)=1.01, p=.42$.

Table 1. Pre-test means and standard deviations for RULER and eLearning groups at baseline

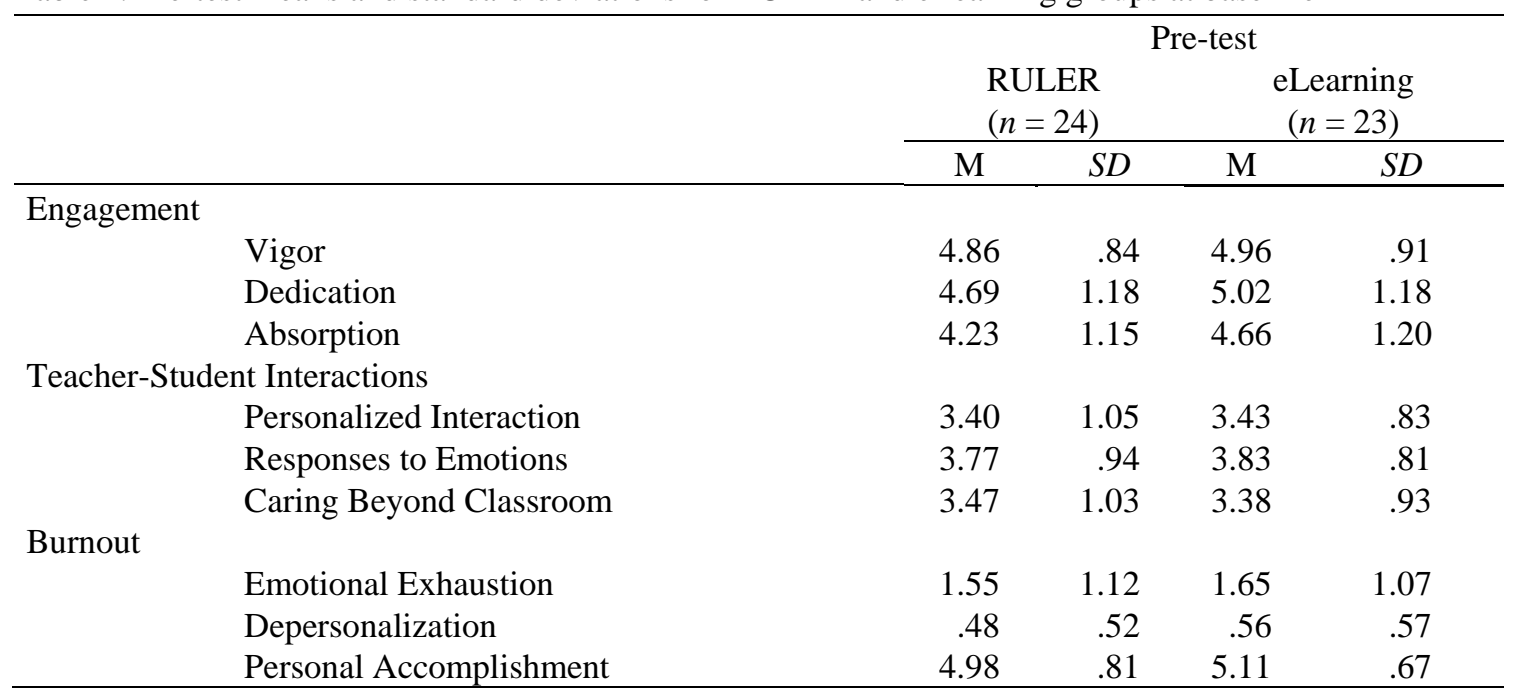

Table 2 reports the means and standard deviations at Time 2. Results of the three separate MANCOVAs resulted in two main effects for condition: Teachers in the RULER group as compared to the eLearning group had higher scores on engagement, Wilk's lambda $(3,31)=5.68, p=.003 ; \eta^{2}=.35$ and teacher-student interactions, Wilk's lambda $(3,31)=6.18, p=.002 ; \eta^{2}=.37$; but not on measures of burnout, Wilk's lambda $(3,31)=1.90, p=.15$; $\eta^{2}=.15$.

Univariate tests showed that the RULER group as compared to the eLearning group had statistically significant higher scores on: two dimensions of engagement: vigor $F(1,33)=8.11, p=.008$; and absorption, $F(1,33)=$ $7.10, p=.01$; all three dimensions of teacher-student interactions: personalized interactions $F(1,33)=12.60, p$ $=.001 ;$ responses to emotions $F(1,33)=7.29, p=.01$, and caring beyond the classroom $F(1,33)=14.36, p$ $=.001$; and on just the dimension of lower burnout: personal accomplishment $F(1,33)=5.19, p=.03$. 
Table 2. Post intervention group differences on all outcomes

\begin{tabular}{|c|c|c|c|c|c|c|}
\hline & \multicolumn{2}{|c|}{$\begin{array}{l}\text { RULER } \\
(n=24)\end{array}$} & \multicolumn{2}{|c|}{$\begin{array}{l}\text { eLearning } \\
(n=23)\end{array}$} & \multirow[b]{2}{*}{$p$} & \multirow[b]{2}{*}{$\eta^{2}$} \\
\hline & $M$ & $S D$ & $M$ & $S D$ & & \\
\hline \multicolumn{7}{|l|}{ Engagement } \\
\hline Vigor & 5.10 & .57 & 4.77 & 1.04 & .008 & .20 \\
\hline Dedication & 4.92 & .95 & 4.91 & .94 & .380 & .02 \\
\hline Absorption & 4.72 & .91 & 4.30 & 1.35 & .012 & .18 \\
\hline \multicolumn{7}{|l|}{ Teacher Student Interaction } \\
\hline Personalized Interactions & 3.90 & .90 & 3.45 & .85 & .001 & .28 \\
\hline Responses to Emotions & 4.11 & .82 & 3.69 & .85 & .010 & .18 \\
\hline Caring Beyond Classroom & 3.93 & .85 & 3.43 & .92 & .001 & .30 \\
\hline \multicolumn{7}{|l|}{ Burnout } \\
\hline Emotional Exhaustion & 1.37 & 1.13 & 1.63 & 1.17 & .380 & .02 \\
\hline Depersonalization & .42 & .74 & .76 & .93 & .090 & .09 \\
\hline Personal Accomplishment & 5.12 & .63 & 4.86 & .71 & .031 & .14 \\
\hline
\end{tabular}

Note. Gender, age, trait affect, personality, and baseline scores were included as covariates in all analyses.

\section{Discussion}

This study provides further support for the positive impact of one evidence-based SEL program, RULER, on teacher development (Brackett et al., 2011). Consistent with our hypothesis, participants who attended the RULER training as compared to the eLearning training, had more positive scores on several outcomes related to teacher engagement, positive interactions with students, and burnout. All of the findings remained statistically significant after controlling for trait affect and personality, dimensions traditionally related to engagement and burnout among teachers (Carson et al., 2011; Langelaan et al., 2006). The positive findings on teacher-student interaction scales and teacher performance in this study are consistent with results of a large randomized controlled trial of RULER, which showed significant shifts in classroom emotional climate, as measured by valid observational tools (Rivers et al., 2013). These results also provide support of the positive impact that evidence-based SEL programs can have in academic environments different from those where they have been developed.

\subsection{Effects on Teacher Engagement}

With respect to engagement, a critical skill associated with student achievement and other important outcomes (Canrinus et al., 2012; Cornelius-White, 2007; Patrick et al., 2000; Van Uden, Ritzen, \& Pieters, 2013), teachers in the RULER as opposed to the eLearning group had higher post-test ratings on two of the three dimensions of engagement: vigor and absorption, but not dedication. Vigor is associated with higher levels of energy and resilience while working, a general investment in in one's work, and persistence in the face of difficulties. Absorption is associated with full concentration and engagement in one's work. It is possible that one of the RULER Anchor Tools, the Mood Meter, might have helped teachers to achieve higher levels of engagement in these areas. The Mood Meter gives teachers strategies to build emotional self-awareness and techniques to integrate emotions into daily instruction in order to achieve desired classroom goals. In addition, the Meta-Moment, which focuses on self-regulation, might have helped to improve teacher vigor through the development of effective strategies to manage difficult feelings. Future research should examine whether these shifts in teacher ratings of engagement lead teachers to creating more challenging lessons that are tailored to their students' needs. This also would permit the testing of whether SEL training leads to increases in students' motivation to learn and greater academic performance.

It is unclear why there were no significant differences in dedication. It is possible that this component of engagement, which includes a sense of significance, inspiration, and pride, might be a distal outcome of SEL training or less susceptible to change as a result of SEL training.

\subsection{Effects on Teacher-Student Interactions}

At the end of the training period, teachers in the RULER as compared to eLearning group had higher ratings on the all three aspects of teacher-student interactions. These findings have important implications for student achievement and overall classroom functioning. For example, implementing an SEL program appears to enhance teachers' ability to make personal connections, respond more effectively to students' emotions, including sensitivity to their students' needs and real concern for their students beyond academic matters. One of the RULER Anchor Tools, the Charter, which was designed to help teachers enhance the classroom climate might 
have facilitated these differences. The Charter is a collaborative, "live" document that outlines how its members aspire to treat each other. Teachers and their students create classroom charters that include the feelings that students and educators want to experience in school, the behaviors that foster those feelings, and guidelines for both preventing and managing unwanted feelings and conflict. By working together on the Charter, everyone understands how their actions affect the learning community and how to work together to create a positive classroom climate.

The present findings also point to the potential value of developing teachers' SEL skills before they implement an SEL program. Direct training in SEL for teachers can help them to learn effective strategies to both understand and manage emotions, which might lead to more optimal, caring and supportive interactions with their students and colleagues. One study, for example, showed that teachers who implemented an SEL program with poor quality had students with less favorable outcomes than teachers who implemented the program with high quality (Reyes, Bracket, Rivers, Elberton, \& Salovey, 2012). Moreover, teachers' empathy and feelings of unconditional positive regard predict school adjustment and academic achievement among students (Baker, 2006; Cornelius- White, 2007; Hamre \& Pianta, 2001; Wubbels \& Brekelmans, 2006). In general, it appears that SEL training has the potential to improve teaching pedagogy, social interactions, and personal development by addressing a set of emotion-focused strategies that contribute to better classroom functioning and consequently, positive student development (Hagelskamp et al., 2013).

\subsection{Effects on Teacher Burnout}

Finally, in partial support of our hypotheses, teachers in the RULER as compared to the eLearning group had higher scores on just one of the three burnout scales: personal accomplishment, but not on depersonalization and emotional exhaustion. Personal accomplishment taps teachers' feelings of self-efficacy and success in their jobs. Because SEL and RULER, in particular, was something new for teachers, it is possible that exposure to new tools that promote SEL, and success using them, enhanced their feelings of personal accomplishment. It is unclear why SEL training did not have an impact on depersonalization and emotional exhaustion. It is possible that both range restriction and social desirability response bias on depersonalization influenced the results on this outcome. Very few teachers endorsed items such as "I feel I treat some students as if they were impersonal objects." With respect to emotional exhaustion, it is possible that more time and practice with RULER tools are necessary before teachers report being less drained by work demands. Finally, the lack of findings on the negative dimensions of burnout might have been due to the lower levels of burnout in this sample of teachers compared to the general population (Betoret, 2009).

\subsection{Limitations and Future Directions}

The current research is not without limitations. First, the sample size was too small to draw any large conclusions. This also made it difficult to examine possible differences among preschool, primary or secondary teachers, male versus female teachers, and novice versus experience teachers. Nevertheless, even with these limitations effect sizes were still larger (range $=.15$ to .37 ) than those found in previous SEL research (Durlak, et al., 2011). A second, major limitation is that participants were not assigned randomly to condition; we only were able to include a comparison group that received an equivalent amount of training in terms of hours and dedication. The inclusion of a third condition in which teachers received no training also would have improved the design of this study. A third limitation, is that teachers who chose RULER likely were more motivated to receive SEL training than those who chose eLearning, and therefore were more prone to change teacher-related dimensions directly related to social and emotional functioning in their classrooms. It is worth mentioning, however, that the teachers in each group were equivalent at baseline on all measures. Additionally, we were not able to keep regular communication with the comparison group during the eLearning training. A fourth limitation is that teachers provided self-ratings on all variables. While past research shows that teachers' self-perceptions of school climate are important and influence their motivation, well-being and social interactions (Collie, Sampkha, \& Perrie, 2012; Wubbels \& Brekelmans, 2006), ideally a larger battery of measures, including both objective measures and student ratings of classroom quality would be included in future research. The inclusion of student-level outcomes would help to examine the possible mediating influences of enhanced teacher outcomes on student achievement and behavior. Finally, it will be important to compare RULER to other SEL interventions that focus on adult development in order to advance the understanding of the possible mechanisms underlying improvements in teaching practices that result of SEL programming.

\subsection{Conclusion}

This pilot study was the first to investigate whether RULER, an evidence-based SEL program was associated with teacher-related workplace outcomes in Spain. While preliminary, this research helps to advance the 
validation of SEL programs in socio-cultural contexts outside the United States. Moreover, this research supports the notion that teacher abilities, performance, and practices can be enhanced through targeted SEL programs. More research is needed to test how SEL training improves teaching and learning practices and the classroom environments in which they occur.

Declaration of Conflicting Interests

The third author receives royalties on RULER materials.

Funding source

The current study was conducted with support from the project "Preventing Violence and Psychosocial Maladjustment in the Classroom Environment through Emotional Intelligence Education (SEJ-03036)" founded by the Department of Economy, Innovation and Science of Spain. Trainings also were supported by grants from the Teacher Resources Center of the Spanish Department of Education.

\section{References}

Baker, J. A. (2006). Contributions of teacher-child relationships to positive school adjustment during elementary school. Journal of School Psychology, 44(3), 211-229. http://dx.doi.org/10.1016/j.jsp.2006.02.002

Benet-Martínez, V., \& John, O. P. (1998). Los cinco grandes across cultures and ethnic groups: Multitrait-multimethod analyses of the big five in spanish and english. Journal of Personality and Social Psychology, 75(3), 729-750. http://dx.doi.org/10.1037/0022-3514.75.3.729

Betoret, F. D. (2009). Self-efficacy, school resources, job stressors and burnout among spanish primary and secondary school teachers: A structural equation approach. Educational Psychology, 29(1), 45-68. http://dx.doi.org/10.1080/01443410802459234

Borg, M. G., Riding, R. J., \& Falzon, J. M. (1991). Stress in teaching: A study of occupational stress and its determinants, job satisfaction and career commitment among primary schoolteachers. Educational Psychology, 11(1), 59-75. http://dx.doi.org/10.1080/0144341910110104

Brackett, M. A., Rivers, S. E., Maurer, M., Elbertson, N. A., \& Kremenitzer, J. P. (2011). Creating emotionally literate learning environments. In M. A. Brackett, J. P. Kremenitzer, M. Maurer, S. E. Rivers, N. A. Elberston \& M. D. Carpenter (Eds.), Creating emotionally literate learning environments (pp. 1-21). Port Chester, NY: National Professional Resources, Inc.

Brackett, M. A., Palomera, R., Mojsa-Kaja, J., Reyes, M. R., \& Salovy, P. (2010). Emotion-regulation ability, burnout, and job satisfaction among british secondary-school teachers. Psychology in the Schools, 47(4), 406-417. Retrieved from http://search.proquest.com/docview/622169747? accountid=14568

Brackett, M. A., Rivers, S. E., Reyes, M. R., \& Salovey, P. (2012). Enhancing academic performance and social and emotional competence with the RULER feeling words curriculum. Learning and Individual Differences, 22(2), 218-224. http://dx.doi.org/10.1016/j.lindif.2010.10.002

Canrinus, E. T., Helms-Lorenz, M., Beijaard, D., Buitink, J., \& Hofman, A. (2012). Self-efficacy, job satisfaction, motivation and commitment: Exploring the relationships between indicators of teachers' professional identity. European Journal of Psychology of Education, 27(1), 115-132. http://dx.doi.org/10.1007/s10212-011-0069-2

Carson, R. L., Plemmons, S., Templin, T. J., \& Weiss, H. M. (2011). "You are who you are:" A mixed-method study of affectivity and emotion regulation in curbing teacher burnout. (pp. 239-265). Charlotte, NC, US: IAP Information Age Publishing, Charlotte, NC. Retrieved from http://search.proquest.com/docview/922508752?accountid=14568

Castillo, R., Salguero, J. M., Fernández-Berrocal, P., \& Balluerka, N. (2013). Effects of an emotional intelligence intervention on aggression and empathy among adolescents. Journal of Adolescence, 36(5), 883-892. http://dx.doi.org/10.1016/j.adolescence.2013.07.001

Collie, R., Sampkha, J., \& Perrie, N. (2012). School climate and social-emotional learning: predicting teacher stress, job satisfaction, and teaching efficacy. Journal of Educational Psychology, 104(4), 1189-1204. http://dx.doi.org/10.1037/a0029356

Cornelius-White, J. (2007). Learner-centered teacher-student relationships are effective: A meta-analysis. Review of Educational Research, 77(1), 113-143. http://dx.doi.org/10.3102/003465430298563

den Brok, P., Brekelmans, M., \& Wubbels, T. (2004). Interpersonal teacher behavior and student outcomes. 
School effectiveness and School Improvement, 15, 407-422. http://dx.doi.org/10.1080/09243450512331383262

Durlak, J. A., Weissberg, R. P., Dymnicki, A. B., Taylor, R. D., \& Schellinger, K. B. (2011). The impact of enhancing students' social and emotional learning: A meta - analysis of school - based universal interventions. Child Development, 82(1), 405-432. http://dx.doi.org/10.1111/j.1467-8624.2010.01564.x

El Hassan, K., \& Mouganie, Z. (2013). Implementation of the social decision-making curriculum on primary students (Grades 1-3) in Lebanon. School Psychology International, 1-9. http://dx.doi.org/10.1177/0143034312469758.

Elvira, J. A. M., \& Cabrera, J. H. (2004). Estrés y burnout en profesores. International Journal of Clinical and Health Psychology, 4(3), 597-621. $\quad$ Retrieved from http://search.proquest.com/docview/620535221?accountid=14568

Fredrickson, B. L. (2000). Cultivating positive emotions to optimize health and well-being. Prevention \& Treatment, 3(1). http://dx.doi.org/10.1037/1522-3736.3.1.31a

Greenberg, M. T., Weissberg, R. P., O'Brien, M. U., Zins, J. E., Fredericks, L., Resnik, H., \& Elias, M. J. (2003). Enhancing school-based prevention and youth development through coordinated social, emotional, and $\begin{array}{lllll}\text { academic learning. } & \text { American }\end{array}$ http://dx.doi.org/10.1037/0003-066X.58.6-7.466

Hagelskamp, C., Brackett, M. A., Rivers, S. E., \& Salovey, P. (2013). Improving classroom quality with the ruler approach to social and emotional learning: Proximal and distal outcomes. American Journal of Community Psychology. http://dx.doi.org/10.1007/s10464-013-9570-x

Hakanen, J. J., Bakker, A. B., \& Schaufeli, W. B. (2006). Burnout and work engagement among teachers. Journal of School Psychology, 43(6), 495-513. http://dx.doi.org/10.1016/j.jsp.2005.11.001

Hamre, B. K., \& Pianta, R. C. (2001). Early teacher-child relationships and the trajectory of children's school outcomes through eighth grade. Child Development, 72(2), 625-638. http://dx.doi.org/10.1111/1467-8624.00301

Hamre, B. K., \& Pianta, R. C. (2005). Can instructional and emotional support in the first-grade classroom make a difference for children at risk of school failure? Child Development, 76(5), 949-967. http://dx.doi.org/10.1111/j.1467-8624.2005.00889.x

Hargreaves, A. (2000). Mixed emotions: Teachers' perceptions of their interactions with students. Teaching and Teacher Education, 16(8), 811-826. http://dx.doi.org/10.1016/S0742-051X(00)00028-7

Humphrey, N., Kalambouka, A., Wigelsworth , M., \& Lendrum, A. (2010). Going for goals: an evaluation of a short, social-emotional intervention for primary school children. School Psychology International, 31(3), 250-270. http://dx.doi.org/10.1177/0143034309352578

Hutchings, J., Bywater, T., Gridley, N., Whitaker, C., Martin-Forbes, P., \& Gruffydd, S. (2011). The incredible years therapeutic social and emotional skills programme: a pilot study. School Psychology International, 1-9. http://dx.doi.org/10.1177/0143034311415899

John, O. P., Donahue, E. M., \& Kentle, R. L. (1991). The Big Five Inventory--Versions 4a and 54. Berkeley, CA: University of California, Berkeley, Institute of Personality and Social Research.

Johnson, S., Cooper, C., Cartwright, S., Donald, I., Taylor, P., \& Millet, C. (2005). The experience of work-related stress across occupations. Journal of Managerial Psychology, 20(2), 178-187. http://dx.doi.org/10.1108/02683940510579803

Klassen, R., Wilson, E., Siu, A. F. Y., Hannok, W., Wong, M. W., Wongsri, N., . . J Jansem, A. (2012). Preservice teachers' work stress, self-efficacy, and occupational commitment in four countries. European Journal of Psychology of Education. http://dx.doi.org/10.1007/s10212-012-0166-x

Langelaan, S., Bakker, A. B., van Doornen, L. J. P., \& Schaufeli, W. B. (2006). Burnout and work engagement: Do individual differences make a difference? Personality and Individual Differences, 40(3), 521-532. http://dx.doi.org/10.1016/j.paid.2005.07.009

Maslach, C., Jackson, S., \& Leiter, M. P. (1996). Maslach Burnout Inventory (3rd ed.). Palo Alto,CA: Consulting Psychologists Press.

Mayer, J. D., \& Salovey, P. (1997). What is emotional intelligence? In P. Salovey, \& D. J. Sluyter (Eds.), 
Emotional development and emotional intelligence: Educational implications (pp. 3-34). New York, NY: Basic Books, Inc.

Patrick, B. C., Hisley, J., \& Kempler, T. (2000). "What's everybody so excited about?": The effects of teacher enthusiasm on student intrinsic motivation and vitality. Journal of Experimental Education, 68(3), 217-236. doi: $10.1080 / 00220970009600093$

Patrick, H., Ryan, A. M., \& Kaplan, A. (2007). Early adolescents' perceptions of the classroom social environment, motivational beliefs, and engagement. Journal of Educational Psychology, 99(1), 83-98. doi: 10.1037/0022-0663.99.1.83

Pianta, R. C., Belsky, J., Vandergrift, N., Houts, R., \& Morrison, F. J. (2008). Classroom effects on children's achievement trajectories in elementary school. American Educational Research Journal, 45(2), 365-397. doi: 10.3102/0002831207308230

Reyes, M. R., Brackett, M. A., Rivers, S. E., Elbertson, N. A., \& Salovey, P. (2012). The interaction effects of program training, dosage, and implementation quality on targeted student outcomes for the RULER approach to social and emotional learning. School Psychology Review, 41(1), 82-99. Retrieved from $\mathrm{http}: / /$ search.proquest.com/docview/1011856402?accountid=14568

Reyes, M. R., Brackett, M. A., Rivers, S. E., White, M., \& Salovey, P. (2012). Classroom emotional climate, student engagement, and academic achievement. Journal of Educational Psychology, 104(3), 700-712. http://dx.doi.org/10.1037/a0027268

Rivers, S. E., Brackett, M. A., Reyes, M. R., Elbertson, N. A., \& Salovey, P. (2013). Improving the social and emotional climate of classrooms: A clustered randomized controlled trial testing The RULER Approach. Prevention Science, 14(1), 77-87. http://dx.doi.org/10.1007/s11121-012-0305-2

Ruiz-Aranda, D., Castillo, R., Salguero, JM., Cabello, R., Fernández- Berrocal, P., \& Balluerka, N. (2012). Short and midterm effects of emotional intelligence training on adolescent mental health. Journal of Adolescence Health, 51, 462-467. http://dx.doi.org/10.1016/j.jadohealth.2012.02.003

Schaufeli, W. B., Salanova, M., González-Romá, V., \& Bakker, A. B. (2002). The measurement of engagement and burnout: A two sample confirmatory factor analytic approach. Journal of Happiness Studies, 3(1), 71-92. http://dx.doi.org/10.1023/A:1015630930326

Sutton, R. E. (2004). Emotional regulation goals and strategies of teachers. Social Psychology of Education, 7(4), 379-398. http://dx.doi.org/10.1007/s11218-004-4229-y

Sutton, R. E., \& Wheatley, K. F. (2003). Teachers' emotions and teaching: A review of the literature and directions for future research. Educational Psychology Review, 15(4), 327-358. http://dx.doi.org/10.1023/A:1026131715856

Travers, C. J. (2001). Stress in teaching: Past, present and future. In J. Dunham (Ed.), (pp. 130-163). Philadelphia, PA, US: Whurr Publishers. Retrieved from http://search.proquest.com/docview/619761380?accountid=14568

Travers, C. J., \& Cooper, C. L. (1993). Mental health, job satisfaction and occupational stress among UK teachers. Work \& Stress, 7(3), 203-219. http://dx.doi.org/10.1080/02678379308257062

Van Uden, J. M., Ritzen, H., \& Pieters, J. M. (2013). I think I can engage my students. teachers' perceptions of student engagement and their beliefs about being a teacher. Teaching and Teacher Education, 32, 43-54. http://dx.doi.org/10.1016/j.tate.2013.01.004

Watson, D., Clark, L. A., \& Tellegen, A. (1988). Development and validation of brief measures of positive and negative affect: The PANAS scales. Journal of Personality and Social Psychology, 54(6), 1063-1070. http://dx.doi.org/10.1037/0022-3514.54.6.1063

Wubbels, T., \& Brekelmans, M. (2006). Two decades of research on teacher-student relationships in class. International Journal of Educational Research, 43, 6-24. http://dx.doi.org/10.1016/j.ijer.2006.03.003

Zins, J. E., Weissberg, R. P., Wang, M. C., \& Walberg, H. J. (Eds.). (2004). Building academic success on social and emotional learning: What does the research say? New York: Teachers College Press.

\section{$(\mathrm{cc}) \mathrm{BY}$}

This work is licensed under a Creative Commons Attribution 3.0 License. 